УДК 378(091)(571.54)

DOI: $10.18101 / 1994-0866-2019-4-3-9$

\title{
БЫТЬ В ПОИСКЕ НОВЫХ ИДЕЙ
}

\section{(C) Осинский Иван Иосифович}

доктор философских наук, профессор, Бурятский государственный университет имени Доржи Банзарова Россия, 670000, г. Улан-Удэ, ул. Смолина, 24а

E-mail: intellige2007@rambler.ru

В статье рассматриваются вопросы развития научных исследований в Бурятском государственном университете, в частности, роль в этом процессе сборников научных трудов под общим названием «Вестник Бурятского государственного университета», в том числе по проблемам философии, социологии, политологии, культурологии. Анализируются развитие издательской деятельности по названным направлениям, совершенствование дисциплинарной структуры журнала, рост численности и расширение географии авторского состава, превращение «Вестника» в признанное, авторитетное в России и за ее пределами научное издание. В журнале обсуждаются актуальные философские, социологические, политологические, культурологические проблемы, отражаются результаты работ как крупных отечественных и зарубежных ученых, так и молодых, начинающих исследователей. Журнал играет значимую роль не только в системе средств развития науки, но и в подготовке высококвалифицированных научных кадров - кандидатов и докторов философских и социологических наук; он входит в перечень соответствующих ваковских изданий. С 2019 г. журнал стал однопрофильным философским изданием.

Ключевые слова: философия; проблемы; «Вестник»; ученые; общество; глобализация; евразийство; духовность; человек; редколлегия.

\section{Для цитирования}

Осинский И. И. Быть в поиске новых идей // Вестник Бурятского государственного университета. Философия. 2019. Вып. 4. С. 3-9.

Прошло 22 года как вышел первый номер Вестника Бурятского государственного университета. В 1997 г. было принято решение об учреждении сборников научных трудов под общим названием «Вестник Бурятского университета». Это было продиктовано возросшим научным потенциалом вуза (в университете трудилось около 700 ученых, в том числе более 80 докторов наук, профессоров и более 300 кандидатов наук, доцентов), развитием ряда актуальных научных направлений, усилением интеграции вузовской науки с академической, увеличившейся потребностью ученых в публикации результатов своих трудов.

Решение об издании «Вестника» было принято в трудное, кризисное для страны время, когда и без того немногочисленные научные издания одно за другим прекращали свое существование. Уменьшались тиражи журналов, которые продолжали издаваться, сокращались их объемы. Поэтому учреждение периодического научного издания в БГУ имело очень большое значение не только для исследователей нашего университета, но и для ученых всей республики $[1$, с. 5].

На начальном этапе издавалось 9 серий по одному выпуску в год. Первый выпуск журнала состоялся в 1997 г. Нашему журналу была присвоена «Серия 5. Философия. Социология. Политология. Культурология». Были образованы и 
утверждены ученым советом университета редакционный совет (председатель ректор, д-р пед. наук, проф. С. В. Калмыков, зам. председателя - проректор, д-р биол. наук, проф. Ц. З. Доржиев) и редакционная коллегия серии: д-р филос. наук, проф. И. И. Осинский (главный редактор), д-р филос. наук, проф. Л. Л. Абаева (зам. главного редактора), д-р филос. наук, проф. В. И. Затеев (зам. главного редактора), канд. филос. наук, доц. М. В. Золхоева (ответственный секретарь), д-р филос. наук, проф. В. А. Балханов, В. В. Мантатов (позже назначенный зам. главного редактора), Ю. Б. Рандалов, Л. Е. Янгутов, канд. ист. наук, доц. Б. П. Крянев.

В первом выпуске было напечатано 12 статей. Преобладающая часть опубликованных работ (9) была посвящена философским проблемам, 3 статьи - вопросам социологии. В том же номере были две статьи, посвященные юбилейным датам крупных советских, российских ученых-обществоведов: 80-летию доктора философских наук, профессора, члена-корреспондента РАН М. Н. Руткевича и 70-летию доктора философских наук, профессора В. С. Семенова.

Выход первого номера журнала стал знаменательным событием в научной жизни республики. Он вызвал живой отклик не только в Бурятии, но и за ее пределами. В частности, на создание журнала и выход его первого номера отозвалась редколлегия главного российского социологического журнала «Социологические исследования» (СОЦИС): «СОЦИС сердечно поздравляет редколлегию и читателей «Вестника Бурятского государственного университета» (Серия 5) с рождением столь необходимого и перспективного издания. Желаем глубокого и обстоятельного анализа проблем российского общества. Надеемся на тесное творческое сотрудничество. От имени редколлегии журнала «СОЦИС» главный редактор чл.кор. Ж. Тощенко» $[1$, с. 6].

В процессе функционирования издания происходили изменения в его дисциплинарной структуре, периодичности, объемах. Так, в 2003 г. политология и культурология были выделены и образовали собственную отдельную серию. Пятая серия, включающая философию и социологию, просуществовала до 2006 г. (за это время было издано 4 выпуска журнала). В 2007 г. было принято решение об укрупнении изданий, изменении их формата и нумерации. С этого года «Вестник» приобрел прежнюю дисциплинарную структуру, включающую философию, социологию, политологию и культурологию. Он стал выходить 2 раза в год, а с 2009 г. 4 раза. Были и другие изменения, связанные с увеличением географии авторского состава, расширением тематики публикуемых материалов, а главное - повышением качества помещаемых в журнале статей, что способствовало росту его авторитета и статуса. Через несколько лет после начала издания он был включен в «Перечень ведущих рецензируемых научных журналов и изданий Высшей аттестационной комиссии (ВАК), в которых должны быть опубликованы основные научные результаты диссертаций на соискание ученых степеней доктора и кандидата наук». В настоящее время «Вестник» - это признанный профессиональный научный журнал с ярко выраженными чертами общегуманитарного, а точнее, общекультурного издания. Он востребован в среде специалистов по философии, социологии, политологии, других отраслей знаний России и зарубежья. Его получают библиотеки РАН, МГУ им. М. В. Ломоносова, Российская государственная библиотека, библиотека Конгресса США и др.

На начальных этапах издания «Вестника» было немало трудностей. С самого начало приходилось овладевать опытом самофинансировния, так как университет 
плохо финансировался, несовершенной была полиграфическая база вуза, отсутствовал опыт организации подобного вида издания как у редколлегии журнала, так и у работников университетского издательства.

Не случайно первые пять лет выходил журнал по одному номеру в год, с 2003 г. — по два, с 2009 - по четыре. С 1997 по 2018 г. включительно издано 48 номеров. Увеличились его формат и объем. Сначала формат составлял $60 * 841 / 16$, позже $60 * 84$ 1/8. Объем первого номера Вестника (1997) равнялся 9,36 условнопечатных листа, объем же выпуска «Вестника» № 6а (2009) — 46, 72 условно-печатных листа.

Работа над журналом сопровождалась ростом его авторского состава. Если в первом номере было напечатано 12 статей, авторами которых были в основном преподаватели вузов г. Улан-Удэ, то уже в «Вестнике» № 6а (2009) было помещено 86 статей. Число авторов составило 94 человека, представлявших не только Бурятию, но другие города - Иркутск, Красноярск, Екатеринбург, Томск, Сургут, Белгород, Хабаровск, Москва, Саратов и т. д.

«Вестник» со временем превратился, по существу, во всероссийское издание. В журнал присылали свои научные наработки ученые многих научных центров страны. Немало публиковалось статей представителей Сибири, особенно Байкальского региона. В журнале помещались статьи и ряда зарубежных авторов (Китая, Монголии, Украины, США, Польши, Кыргызстана, Грузии), что позволяло следить за развитием научной мысли в других странах. В «Вестнике» печатались результаты исследований по широкому кругу философских, социологических, политологических и культурологических проблем. О количестве опубликованных в журнале статей по указанным отраслям знаний дают представление следующие показатели.

Количество статей «Вестника» (серия 5) по дисциплинам (1997-2018 гг.)

Таблий 1

\begin{tabular}{|l|l|l|l|l|l|l|l|l|}
\hline & \multicolumn{2}{|c|}{$1997-2007$} & \multicolumn{2}{c|}{$2008-2012$} & \multicolumn{2}{c|}{ 2013-2018 } & \multicolumn{2}{c|}{$1997-2018$} \\
\hline & $\begin{array}{l}\text { кол-во } \\
\text { стат. }\end{array}$ & в \% & $\begin{array}{l}\text { кол-во } \\
\text { стат. }\end{array}$ & в \% & $\begin{array}{l}\text { кол-во } \\
\text { стат. }\end{array}$ & в \% & $\begin{array}{l}\text { кол-во } \\
\text { стат. }\end{array}$ & в \% \\
\hline $\begin{array}{l}\text { Фило- } \\
\text { софия }\end{array}$ & 201 & 59,8 & 423 & 42,6 & 441 & 67,4 & 1065 & 52,5 \\
\hline $\begin{array}{l}\text { Социо- } \\
\text { логия }\end{array}$ & 111 & 29,1 & 275 & 27,7 & 88 & 13,4 & 474 & 23,4 \\
\hline $\begin{array}{l}\text { Поли- } \\
\text { толо- } \\
\text { гия }\end{array}$ & 13 & 3,4 & 194 & 19,5 & 53 & 8,1 & 260 & 12,8 \\
\hline $\begin{array}{l}\text { Куль- } \\
\text { туроло- } \\
\text { гия }\end{array}$ & 56 & 14,7 & 101 & 10,2 & 72 & 11,00 & 229 & 11,3 \\
\hline Итого & 381 & 100,00 & 993 & 100,00 & 654 & 100,00 & 2028 & 100,00 \\
\hline
\end{tabular}

Из таблицы видно, что общее количество статей, опубликованных в «Вестнике» (Серия 5) за период 1997-2018 гг. (включительно), составляет 2028. Более половины статей - материалы по философским дисциплинам, четверть - по социологии, столько же по политологии и культурологии. Одной из причин столь значительного преобладания материалов по философии объясняется тем, что 
начиная с 2016 г. журнал стал целиком философским (однопрофильным). Это результат требования Министерства образования и науки РФ - «Вестник» должен быть однопрофильным. Редколлегия с сожалением восприняла это указание. Многочисленная армия социологов, политологов, культурологов лишилась возможности публиковать результаты своих исследований в данном издании. Трудно считать подобное министерское решение разумным, а тем более полезным для ученых Сибири. Зато возникла масса так называемых «высокорейтинговых» издательств, которые за большие деньги публикуют все что угодно. Интернет переполнен обращением «зазывал» подобных «издательств».

Редколлегия «Вестника» обращала внимание на актуальность и новизну публикуемых материалов. Придавалось большое значение статьям, где рассматривались глобальные философские проблемы, их сущность, природа, тенденции, итоги всемирных и всероссийских философских конгрессов. Одно из центральных мест занимали публикации о проблемах современного общества, личности, социальной структуры, этики, экологии, устойчивого развития общества. Традиционно с особым интересом рассматривалась востоковедческая проблематика. В русле данного направления публиковались материалы, посвященные проблемам буддизма, даосизма, конфуцианства, других учений, их гуманитарных ценностям, традициям, влиянию на культуру и традиции Восточной и Центральной Азии [3, с. 4].

Судя по поступающим в журнал материалам, в последние годы усилилось внимание исследователей к проблемам евразийства, духовности в современном российском обществе, смысла жизни, человека, межнациональных и межконфессиональных отношений и другим. Анализ названных проблем нашел свое отражение в целом ряде научных статей.

Значительное количество статей посвящено различным сторонам социальной жизни общества. В них анализируются условия, факторы, динамика социальностратификационной дифференциации социума, его элементов, образа жизни, ценностей. Весомое место занимают исследования, посвященные интеллигенции, ее структуре, роли в жизни общества, а также вопросам молодежи, современной семьи, миграции населения, одиночества, занятости, девиации [3, с. 4]. Злободневной оказалась проблема качества жизни, бедности населения. Она рассмотрена в ряде статей «Вестника». Вместе с тем обращает на себя внимание, что в последние годы произошло значительное уменьшение количества публикаций по социологическим дисциплинам. Если с 2008 по 2011 г. было опубликовано 272 статьи, то с 2012 по 2015 г. - 140, т. е. почти в два раза меньше. Это свидетельствует об ослаблении внимания исследователей Бурятии к вопросам социологии. Что касается политологии и культурологии, то кроме публикаций, указанных в таблице, было издано 3 выпуска «Вестника» - Cер. 16. Политология. Культурология (2004, 2005, 2006 гг.), где была напечатана часть статей по этим направлениям.

В разделе политологии публиковались материалы, посвященные анализу проблем становления новой политической системы общества, его отдельных институтов, особенностей региональной политической власти в национально-государственных образованиях Сибири, специфики формирования многопартийности в сибирских регионах, становления здесь политических элит. Значительная часть материалов посвящена проблемам межрегионального взаимодействия с Китаем, его политике, а также с Монголией [2, с. 3]. Характерным для политологических 
публикаций является активное использование в качестве методов анализа социологических опросов, что придает выдвигаемым теоретическим положениям большую обоснованность и убедительность.

В «Вестнике» значительное место занимают статьи, посвященные культурологическим проблемам. В них наряду с осмыслением теоретико-методологических вопросов культуры анализируются проблемы диалога национальных культур, освещаются исторические особенности возрождения культуры народов Сибири, их менталитет в духовной культуре и др., раскрываются традиционные национальные ценности в сфере культуры многочисленных народов региона [2, с. 4].

В журнале в качестве авторов публикуемых материалов выступали как известные ученые, так и молодые исследователи. Это такие известные зарубежные и российские философы, как академик В. С. Степин, бывший главный редактор журнала «Вопросы философии» В. С. Семенов, президент XXI Всемирного философского конгресса и международной федерации философских обществ, министр культуры Турции И. Кучуради, а также известный российский политолог, профессор МГУ им. М. В. Ломоносова А. П. Бутенко, ректор Житомирского университета (Украина) П. Ю. Саух, известный сибирский культуролог, профессор Л. С. Сысоева. Активными авторами журнала являются обществоведы Бурятии, в их числе профессора В. А. Балханов, В. В. Мантатов, В. И. Затеев, Л. Е. Янгутов, В. И. Антонов, Д. Ш. Цырендоржиева, О. Б. Бальчиндоржиева, А. Н. Постников, П. А. Чукреев, М. И. Добрынина, Ю. А. Серебрякова, О. Б. Истомина, М. В. Бадмаева, кандидаты наук Н. А. Лагойда, К. А. Багаева и др.

В «Вестнике» наряду со статьями принимались материалы круглых столов, периодически организуемых редколлегией. Например, в «Вестнике» № 6а (2009) приводится стенограмма обсуждения итогов XXII Всемирного философского конгресса, состоявшегося в Сеуле (30 июля - 5 августа 2008 г.). В обсуждении принимали участие профессора А. Н. Чумаков, В. В. Мантатов и И. И. Осинский. В «Вестнике» № 3 (Т. 1) 2018 г. в разделе «Научная жизнь» дается анализ работы I Белорусского философского конгресса «Национальная философия в глобальном мире» (18-20 октября 2017 г.). В «Вестнике» № 6 (2016) приводится обзор материалов V Всероссийского социологического конгресса. В «Вестнике» № 3 (Т. 3) 2018 г. в статье профессоров И. И. Осинского и М. И. Добрыниной «Интеллигенция и модернизация социума» - материалы XII Международной научной конференции («Байкальская встреча») «Интеллигенция и проблемы социокультурной модернизации современного общества» (12-16 сентября 2018 г.) и др. Периодически публикуются рецензии на книги, вышедшие как в центральных, так и в местных издательствах.

«Вестник», таким образом, был одним из возможностей отражения результатов научных поисков - идей, гипотез, концепций, теорий в мир науки, тем самым способствовал развитию обществоведческой мысли в России. Он служил местом, где в значительной мере апробировались достоверность, обоснованность выдвигавшихся новых идей, взглядов, представлений. «Вестник» способствовал повышению квалификации, научного статуса исследователей. Многие кандидаты и доктора наук публиковали свои научные труды в данном издании, что, несомненно, позволило им получить искомую ученую степень. 
Конечно, каждая поступившая в журнал рукопись, чтобы стать научной публикацией, проходила путь рецензирования - внутреннего и внешнего, редактирования, доработки (часто неоднократной), печатания. Эту непростую, но весьма ответственную работу выполняли коллектив редколлегии, рецензенты, сотрудники издательства Бурятского государственного университета.

Ее в течение многих лет добросовестно выполняли члены редколлегии: профессора А. Н. Постников, Э. Д. Дагбаев, П. А. Чукреев, Л. Л. Абаева, М. В. Бадмаева (Золхоева), Д. Ш. Цырендоржиева. В последние годы в эту деятельность активно включились доктор философских наук О. Б. Бальчиндоржиева, кандидат философских наук К. А. Багаева. В течение многих лет обязанности ответственного секретаря журнала исключительно добросовестно выполняла А. В. Доржиева.

В состав редакционного совета и редколлегии журнала наряду с отечественными учеными входили и входят известные зарубежные исследователи: профессора П. Я. Саух, Н. А. Козловец (Украина), К. Косела, О. Н. Козлова (Польша). Мы благодарим их за представительство в указанных издательских структурах. Они помогали в отборе качественных статей из своих регионов для «Вестника».

Большая роль в выпуске журнала принадлежит руководителям и сотрудникам издательства - К. А. Баторовой, И. Х. Ошировой, Н. Н. Татарниковой, 3. 3. Ардановой.

Мне, как главному редактору «Вестника», хотелось бы выразить искреннюю признательность всем, кто создавал журнал, помогал совершенствовать качество публикуемых материалов. За все 22 года моего редакторства приходилось читать все поступавшие статьи, как правило, дважды (при их поступлении и принятии решения об издании). Они были разные, тем не менее давали пищу для размышлений. Немало статей вызывали интерес своей новизной, информативностью, умением раскрыть суть проблемы, заинтересовать читателя. Погружение в эти материалы обогащает и редактирующего.

С 2019 г. произошло обновление редколлегии «Вестника». Главным редактором стала заведующая кафедрой философии доктор философских наук М. В. Золхоева (Бадмаева). Передавая эстафету главного редактора журнала, хотелось бы пожелать своей коллеге успехов на этом хлопотном, но интересном поприще.

Мы живем в сложном, противоречивом, динамично меняющемся мире. Очень трудным представляется процесс поиска Россией себя и своего места в этом мире. Хотелось бы, чтобы мы не были равнодушными наблюдателями этого поиска.

\section{Литература}

1. Осинский И. И. Познать собственную судьбу // Вестник Бурятского государственного университета. Философия. Социология. Политология. Культурология. Сер. 5. 1997. Вып. 1. С. 5-8.

2. Осинский И. И. О настоящем и будущем (размышления по поводу выхода 20-го номера «Вестника Бурятского государственного университета») // Вестник Бурятского государственного университета. Философия. Социология. Политология. Культурология. 2009. Вып. 14a. С. 3-4.

3. Осинский И. И. Вестнику 15 лет // Вестник Бурятского государственного университета. Философия. Социология. Политология. Культурология. 2013. № 6. С. 3-4. 


\section{ALWAYS IN THE SEARCH FOR NEW IDEAS}

\section{Ivan I. Osinsky}

Dr. Sci. (Philos.), Prof.,

Dorzhi Banzarov Buryat State University

24a Smolina St., Ulan-Ude 670000, Russia

E-mail: intellige2007@rambler.ru

The article deals with the development of scientific research in Buryat State University, in particular, the role of the collections of scientific articles under the general title "Bulletin of Buryat State University", which concern the problems of philosophy, sociology, political science, and culture. We have analyzed the publishing activities in these fields of knowledge, improvement of the journal structure, an increase in the number of authors and their geographic growth, as well as transformation of "Bulletin" into a recognized, authoritative academic journal in Russia and abroad. The journal discusses current philosophical, sociological, political, cultural problems, presents the research results of both leading domestic and foreign scientists, and young starting researchers. The journal plays a significant role not only in the system of means for the development of science, but also in the training of highly qualified academic personnel - candidates and doctors of philosophical and sociological sciences; it is included in the list of State Commission for Academic Degrees and Titles. Since 2019 the journal has become a single-discipline philosophical serial.

Keywords: philosophy; problems; "Bulletin"; scientists; society; globalization; Eurasianism; spirituality; human; editorial board. 